\title{
A quadrilha de duelo "Anjos do Faroeste" no circuito de festivais folclóricos em Manaus-AM: um olhar etnográfico
}

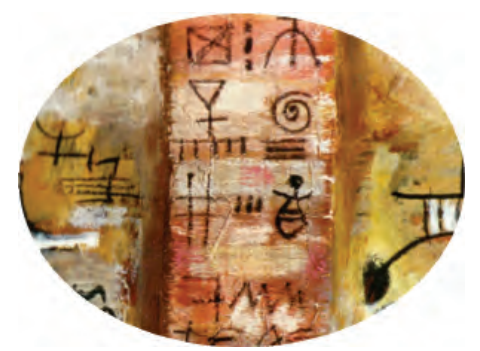

Teresa Kátia Alves de Albuquerque* Dr. Sérgio Ivan Gil Braga**

\section{Resumo}

O presente artigo objetiva apresentar a trajetória do Grupo Folclórico Quadrilha de Duelo "Anjos do Faroeste" da cidade de Manaus-Amazonas no Circuito de Festivais Folclóricos nos bairros durante o período junino. Este estilo de quadrilha junina é típico da cidade de Manaus. A pesquisa foi realizada nos meses de junho e julho de 2011 por meio da descrição etnográfica, com a técnica observação participante.

Palavras-chave: Festejos juninos; festival folclórico; patrimônio imaterial.

\begin{abstract}
This article presents the trajectory of the Folkloric Group Gang Duel "Angels of the Wild West" of the city of Manaus, Amazonas Folklore Festival circuit in the neighborhoods during the junino. This style is typical gang junina the

* Mestranda do Programa de Pós-Graduação Sociedade e Cultura na Amazônia/MINTER-UFAM/UFRR. Professora do Colégio de Aplicação-Centro de Educação da Universidade Federal de Roraima. E-mail: teresa.katia@gmail.com

** Professor do Departamento de Antropologia do Programa de Pós-Graduação em Antropologia Social, do Programa de PósGraduação em Sociedade e Cultura na Amazônia e do Programa de Pós-Graduação em Sociologia (UFAM). Professor da Disciplina Culturas e Imaginários Urbanos ofertada no curso de Mestrado em Sociedade e Cultura na Amazônia em 2011.1. Email: sigbraga@ufam.edu.br.
\end{abstract}


city of Manaus. The survey was conducted during June and July 2011 through ethnographic description, with the participant observation technique.

Keywords: Celebrations juninos; folk festival; intangible heritage.

\section{Festejos juninos: um bem cultural imaterial}

O mês de junho é o período das festanças religiosas e populares em comemoração aos santos católicos: Santo Antonio (13 de junho), São João (24 de junho) e São Pedro ( 29 de junho), e as quadrilhas tem um papel social muito importante, que é enfatizado por Chianca (2010, p. 10) "reafirmam laços sociais importantes, como a vizinhança, a família, o trabalho ou a escola, colaborando para a manutenção de redes sociais fundamentais aos grupos envolvidos". Segundo Amaral (2011) e Braga (2007), este período coincide as celebrações do solstício de verão ${ }^{1}$ na região, propicio para realização de atividades socioeconômicas da região e que beneficiará a vida do homem regional.

O reconhecimento dessas manifestações populares no Brasil iniciou nos anos de 1930 com o modernista Mário de Andrade, que propôs a preservação de processos culturais e de saberes, no âmbito dos ritos, da música, da dança, dos hábitos, das crenças e do folclore, conceitos que somente anos mais tarde seriam classificados como patrimônio imaterial.

Com base em legislações específicas, o Patrimônio Material é composto por um conjunto de bens culturais divididos em bens imóveis como os núcleos urbanos, sítios arqueológicos e paisagísticos e bens individuais; e móveis como coleções arqueológicas, acervos museológicos, documentais, bibliográficos, arquivísticos, videográficos, fotográficos e cinematográficos. Já o Patrimônio Imaterial, são as práticas, representações, expressões, conhecimentos e técnicas que as comunidades, os grupos e, em alguns casos, os indivíduos reconhecem como parte integrante de seu patrimônio cultural, é transmitido de geração em geração e constantemente recriado pelas comuni-

46 Somanlu, ano 11, n. 1, jan./jun. 2011 
dades e grupos em função de seu ambiente, de sua interação com a natureza e de sua história, gerando um sentimento de identidade e continuidade, contribuindo assim para promover o respeito à diversidade cultural e à criatividade humana (FETEC, 2011).

O festejo junino está inserido no patrimônio cultural imaterial na classificação criada pela Constituição de 1988, sendo considerado um conjunto de bens de natureza material e imaterial conceituados pela Organização das Nações Unidas para a Educação, a Ciência e a Cultura - Unesco. O patrimônio imaterial está expresso no artigo 216 da Constituição Federal de 1988,

Constituem o patrimônio cultural brasileiro os bens de natureza material e imaterial, tomados individualmente ou em conjunto, portadores de referência à identidade, à ação e à memória dos diferentes grupos formadores da sociedade brasileira". Entretanto somente em 2000 foi instituído um instrumento legal para a preservação desse patrimônio, o registro de bens culturais de natureza imaterial e criou-se também o Programa do Patrimônio Imaterial por meio do Decreto Federal n ${ }^{\circ} 3.551$ (VADE MECUM, 2010, p. 77-78).

O festejo junino está faz parte da categoria de festas e celebrações que se constitui num bem cultural de natureza imaterial, considerando suas subdivisões, dos quais são destacadas (FETEC, 2011):

- saberes e ofícios tradicionais (conhecimentos e modos de fazer enraizado no cotidiano das comunidades, exemplos: crendices, superstições, lendas, pescador, farinheiras, a culinária local, o artesanato, uso cotidiano e religioso, brinquedos e brincadeiras etc.);

- formas de expressão (manifestações literárias, musicais, plásticas, cênicas e lúdicas);

- festas e celebrações (rituais e festas que marcam a vivência coletiva do trabalho, da religiosidade, do entretenimento e de outras práticas da vida social, exemplos: Festas de padroeiro, da colheita, festas de rua, celebrações cotidianas e periódicas, festejos juninos, de Natal e Ano Novo); 
- lugares de sociabilidade (espaços onde se concentram e se reproduzem práticas culturais coletivas, exemplos: mercados, feiras, santuários, praças, feiras, shopping)

Os bens de natureza imaterial são complexos, pois tratam de bens intangíveis, abstratos como as formas de expressão, os modos de criar os saberes e o fazer da população, que se classificam como cultura tradicional, popular e oral.

Em Manaus, a Secretaria de Cultura do Governo do Estado do Amazonas, desenvolve trabalhos com o objetivo de mapear e registrar os bens culturais de natureza imaterial, por meio de estudos, edital e projetos nas áreas de cultura popular e indígena, caracterizando a vivência cultural de uma comunidade, assim, podemos destacar alguns estudos realizados: Resgate de brinquedos tradicionais urbanos: boneca de pano (bruxa), pião, perna de pau e o jogo de botão de caroço de tucumã utilizado no Largo de São Sebastião; Estudos sobre a utilização cultural e social do tucumã; Estudos sobre os Símbolos do Amazonas; Edital de pesquisa sobre santos e crendices no Amazonas; Pesquisa "Memória do Largo de São Sebastião"; Coleção de postais da série "Patrimônio Cultural Imaterial"; Coleção de postais da série: "Memória do Amazonas"; etc. (GOVERNO DO ESTADO DO AMAZONAS, 2005).

\section{Circuito de Festivais Folclóricos nos bairros em Manaus-AM}

Durante os meses de junho e julho as festanças realizam-se em vários bairros da cidade de Manaus, por exemplo, Parque 10, Penarol, Vila da Prata, Compensa, Alvorada I e II, entre outros, e os grupos folclóricos têm a oportunidade de apresentar à comunidade o seu trabalho, que envolve: coreografia, indumentária, conjunto (coordenação e brincantes), harmonia e o histórico.

A festa que é tradicional na cidade de Manaus é o Festival Folclórico do Amazonas que está na 55a. edição em 2011, que realiza-se no Centro Cultural Povos da Amazônica, na Bola da Superintendência da Zona Franca de Manaus - SUFRAMA ${ }^{2}$. A novidade em 2011 foi o $1^{\circ}$. Festival Folclórico de 
Manaus que no Centro de Convenções, conhecido por Sambódromo (SILVA, 2009). A semelhança entre estes eventos está na apresentação e concursos de danças como: quadrilhas, Ciranda, Cangaço, Garrote, dança Internacional e os bois de Manaus Garanhão, Corre Campo e Brilhante.

A Prefeitura Municipal promoveu em 2011, o $2^{\circ}$. Circuito de Festivais Folclóricos nos mais diversos bairros, sob a coordenação da Fundação Municipal de Eventos e Turismo - Manaustur, com o objetivo levar lazer e entretenimento para as comunidades, além de movimentar a economia da população local na comercialização de comidas e bebidas (SEMCOM, 2011).

A quadrilha de duelo, que será o foco do nosso estudo, está inserida na história da dança de quadrilha junina, sua origem é francesa e chegou ao Brasil no século XIX, identificava na época a contradança, dançada por quatro pessoas (AMARAL, 1998). Desta "quadrilha de quatro" derivou a "quadrilha geral" e, conforme foi se popularizando, o nome "quadrilha" foi sendo cada vez mais usado (CHIANCA, 2010). Para Cascudo (2001), a quadrilha "abria os bailes da corte em qualquer país europeu ou americano, preferida de toda a sociedade".

Portanto, para se compreender como se desenvolve o movimento artístico de um grupo folclórico, será realizada neste estudo a descrição etnográfica das apresentações realizadas pela Quadrilha de Duelo "Anjos do Faroeste" no Circuito de Festivais Folclóricos de bairros na cidade de Manaus, capital do Estado do Amazonas. Não se trata apenas daquela tradicional que é a mais popular, com a encenação sob a presença dos noivos, o pai da noiva, o padre, o juiz (SILVA, 2009), mas apresenta mocinhos, bandidos, xerife, mexicanos, baseado em filmes americanos.

Vale salientar que, o método etnográfico utilizado neste trabalho, exigiu da pesquisadora, durante o período do trabalho de campo, permanecer em contato direto com o Grupo Folclórico Quadrilha de Duelo Anjos do Faroeste, observando cuidadosamente o que as pessoas falavam e o que faziam, além de tentar absorver alguns valores e sentimentos do grupo, acompanhando de perto as atividades relacionadas aos ensaios, os preparativos que antecediam 
as apresentações nos festivais (maquiagem, preparar as indumentárias, entrada no ônibus etc.).

\section{Contato inicial com o grupo folclórico Anjos do Faroeste}

O interesse em observar este grupo folclórico ocorreu a partir do contato inicial, que foi muito inusitado, considerando que estava em busca de um patrimônio cultural ${ }^{3}$ imaterial na cidade de Manaus, Estado do Amazonas AM relacionado aos festejos juninos: uma quadrilha, objetivando desenvolver uma pesquisa etnográfica e descrever os fatos observados em festivais folclóricos, por meio da pesquisa observação participante, estando presente na área em estudo (MALINOWSKI, 1976).

Durante a locomoção num veículo na Avenida Constantino Nery na cidade de Manaus, próximo ao Sambódromo ${ }^{4}$, abordei um casal que estava numa moto, por observar que a senhora na garupa, segurava uma peça de roupa muito colorida, cheia de rendas e muito volumosa. Estávamos aguardando o semáforo "abrir" e procurei saber se essa referida roupa que estava segurando era de quadrilha, positivamente me respondeu. Logo após, paramos os nossos veículos e fomos conversar.

Apresentei-me e expus o projeto que estava desenvolvendo, deixando claro o meu interesse pelo assunto, ou seja, realizar um trabalho etnográfico sobre um patrimônio cultural imaterial na cidade de Manaus - AM. Eles disseram que não se tratava de uma quadrilha tradicional, mas de "duelo" e que se chamava Anjo do Faroeste. Após o nosso diálogo, fui apresentada à coordenação da Quadrilha de Duelo "Anjos do Faroeste", iniciando a pesquisa etnográfica com os brincantes do Bairro São Jorge. Este grupo se apresenta nos festivais folclóricos de bairros durante os meses de junho a agosto.

\section{Histórico da Quadrilha de Duelo em Manaus-AM}

A Quadrilha de Duelo na cidade de Manaus-AM foi criada com características folclóricas, a encenação é baseada no faroeste ${ }^{5}$ americano, podem-

50 Somanlu, ano 11, n. 1, jan./jun. 2011 
se ver xerifes mexicanos, bandidos e mocinhos, sendo que, o tradicional casamento que existe nas apresentações das quadrilhas tradicionais foi substituído por um duelo. ${ }^{6}$ Vale ressaltar que, desde o século XIX, quando chegou ao Brasil, as quadrilhas juninas vêm passando por mudanças e surgindo novas categorias, fato este constatado por Chianca (2010, p. 10),

Hoje existem muitos tipos de quadrilhas além dessa forma mais tradicional descrita acima. A mais conhecida é chamada de "estilizada", e traz muitas modificações a essa base. Nela há uma maior liberdade de coreografia e enredos, além de roupas bem cortadas, maquiagem cuidadosa e inspiração nobre, inclusive na postura corporal dos dançarinos e no recurso a elementos estéticos provenientes da Europa e da América, formando um conjunto que sintetiza uma ruralidade vestimentar luxuosa e autovalorizante, pois esse novo dançarino não é mais um caipira!

É neste sentido de inovação que os quadrilheiros incorporam o universo das nações juninas, celebrando o seu costume originado a tradicional quadrilha Americana totalmente peculiar à cultura brasileira. Segundo Histórico ${ }^{7}$ Quadrilha "Os Anjos do Faroeste",

\begin{abstract}
As quadrilhas americanas evoluíram com o tempo, ousaram na estética e grandiosidade, hoje a brincadeira secular na região Norte do Amazonas e um legado que permite projetar o passado no presente em forma de um espetáculo junino durante dois meses: junho e julho. A quadrilha "Os Anjos do faroeste" mantém a tradição e os ensinamentos dos seus mestres quadrilheiros de Manaus, que tem como símbolo uma asa de anjo, fazendo luz a denominação aos festejos de Santo Antonio, São João e São Pedro (2011, p. 5).
\end{abstract}

Rosinaldo Lopes, criador da Quadrilha de Duelo Anjos do Faroeste, informou que o morador do Bairro São Jorge, Edilson Feitosa, fundou a primeira quadrilha de Duelo há vinte e cinco anos, chama-se "Grupo Folclórico Quadrilha de Duelo os Pistoleiros na Roça" e permanece até os dias de hoje. Segundo Rosinaldo Lopes ${ }^{8}$, o motivo que o levou a criar uma quadrilha desta categoria deve-se ao fato de gostava de filmes de faroeste e quis inovar, criando 
assim, o primeiro grupo folclórico de quadrilha de duelo (Informação verbal). Segundo Luciano Gonçalves de Barros a quadrilha de duelo é típica de Manaus, não há em outros Estados (Informação verbal).

Outros grupos se formaram e realizam várias apresentações pela cidade no período junino, sendo que existem apenas oito, que são:

- Os Anjos do Faroeste, localizado no Bairro São Jorge, Zona Oeste.

- Os Mexicanos na Roça, localizado no Bairro da Paz, Zona Centro-Oeste.

- Os Justiceiros na Roça, localizado no Bairro da Redenção, Zona Centro-Oeste.

- Os Renegados na Roça, localizado no Bairro da Redenção, Zona Centro-Oeste.

- Os Pistoleiros na Roça, localizado no Bairro da Paz, Zona Centro-Oeste.

- Rápidos no gatilho, localizado no Bairro da Redenção, Zona Centro-Oeste.

- Os Pistocandos da Redenção, localizado no Bairro da Redenção, Zona Centro-Oeste.

- Em Busca da Paz, localizado no Bairro da Redenção, Zona Centro-Oeste.

Existe uma pequena diferença nos tipos de adereços utilizados nas apresentações pelos dois últimos grupos: Os Pistocandos da Redenção e Em Busca da Paz, ele brincam com espadas e os demais com armas, ambas produzidas com madeira. Entretanto, torna-se necessário adquirir autorização da polícia local para utilizar as "armas fictícias" nas suas apresentações.

Os títulos das quadrilhas possuem características em comum, a maioria inicia com o artigo definido no plural "Os", com exceção das quadrilhas: Rápidos no Gatilho e Em Busca da Paz. A maioria consta a palavra "Roça”, especialmente as quadrilhas que utilizam nas apresentações as "armas fictícias". Cada uma delas possui seu projeto, onde consta todo o planejamento do seu grupo: síntese do tema, sua história, o roteiro do duelo (apresentação), adereços, indumentárias dos duelistas, descrição das roupas dos brincantes comuns e dos destaques, música, coreografias. Estes projetos são entregues à equipe da coordenação dos festivais folclóricos antes da participação em concursos.

52 Somanlu, ano 11, n. 1, jan./jun. 2011 


\section{O estudo etnográfico do Grupo Folclórico "Anjos do Faroeste”}

O grupo folclórico "Os Anjos do Faroeste" foi fundada no dia 28 de Março de 2007 pelo Sr. Rosinaldo Lopes, que até hoje vem à frente da dança. As reuniões entre a equipe de coordenação do grupo folclórico para definir o tema da encenação, a música, indumentárias, acontecem com bastante antecedência, aproximadamente no mês de novembro do ano anterior.

Todos os anos os quadrilheiros apresentam coreográficas inéditas, sendo este o idioma português baseado nos filmes de faroeste americanos, onde bandidos e mexicanos estavam sempre em luta por alguma causa. Pode-se ver Rei, Rainha, xerifes, mexicanos, bandidos e mocinhos animando as festas tradicionais, lembrando sempre à grande roda e os noivos com seus convidados. A dança visa sempre apresentar indumentária ${ }^{10}$ no estilo do velho oeste que muito lembra o tempo dos mocinhos e bandidos de salão norte-americano.

O símbolo da Quadrilha de Duelo "Os Anjos do Faroeste" consiste numa estrela, que significa o faroeste americano, do personagem "Xerife" e as três cores possuem a sua significação: o verde, as florestas amazônicas, o vermelho, uma homenagem que o criador do grupo folclórico prestou ao Boi Bumbá Garantido, e o branco, a paz (Figura 1).

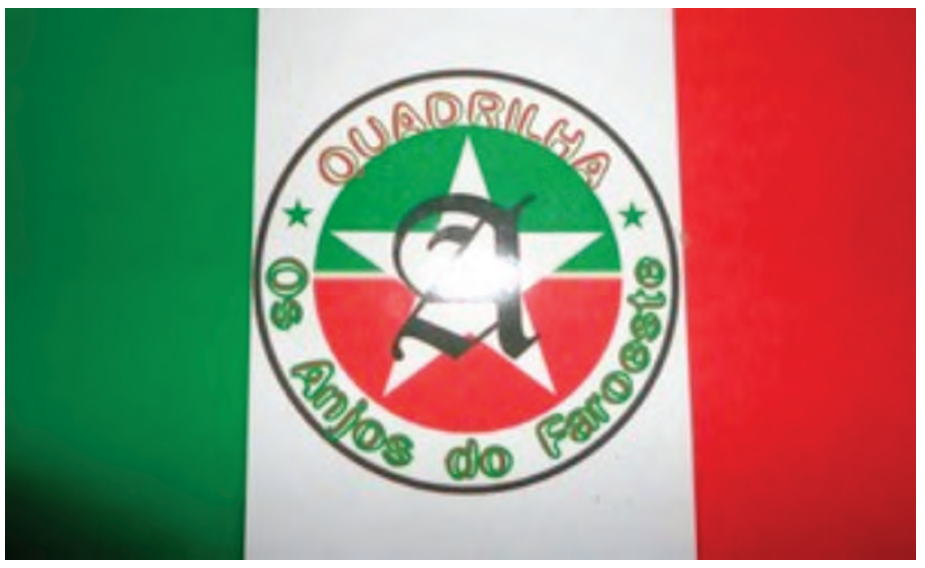

Figura 1. Logotipo.

Fonte: Projeto do Grupo Quadrilha de Duelo, 2011.

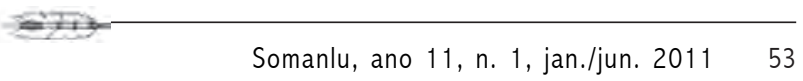


Os ensaios do grupo são realizados na Rua Ermano Estradelli ${ }^{11}$, no Bairro São Jorge, Zona Oeste, em três dias da semana no turno noturno: sexta-feira (22:00 às 23:59 horas); Sábado (21:00 às 23:59 horas); e Domingo (19:00 às 22:00 horas). A equipe é formada por jovens da própria comunidade, os vizinhos e familiares dos dançarinos ficam sentados na calçada observando os ensaios até o seu término. Esta rua é um espaço de sociabilidade, os moradores fazem com que tenha vida, tenha alma, assim, podemos concordar com João do Rio (2007) "Oh, sim, as ruas tem alma! Há ruas honestas, ruas ambíguas, suas sinistras, ruas nobres, delicadas [...]” (p. 30).

Momentos antes do ensaio, a rua é interditada com ícones, os próprios quadrilheiros são responsáveis em inserir no seu início, impedindo assim, a passagem de veículos. Segundo informação da coordenação, este procedimento é legal considerando que possuem documentados expedidos pelos órgãos competentes: Polícia Militar, Instituto Municipal de Trânsito (INTRANS) (Figura 2).

Os quadrilheiros se aquecem assim como em qualquer atividade esportiva. O alongamento do corpo é realizado de forma individualizada ou em dupla. Enquanto isso, o coordenador do grupo instala a caixa de som que fica na calçada e realiza os testes sonoros (Figura 3).

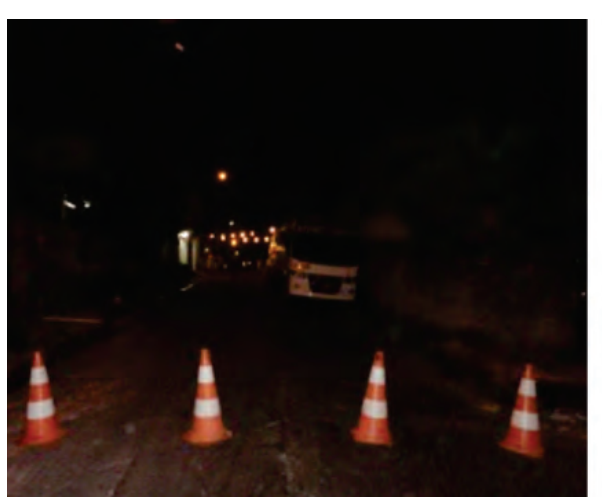

Figura 2. Rua interditada por ícones. Fonte: Acervo da autora, 2011.

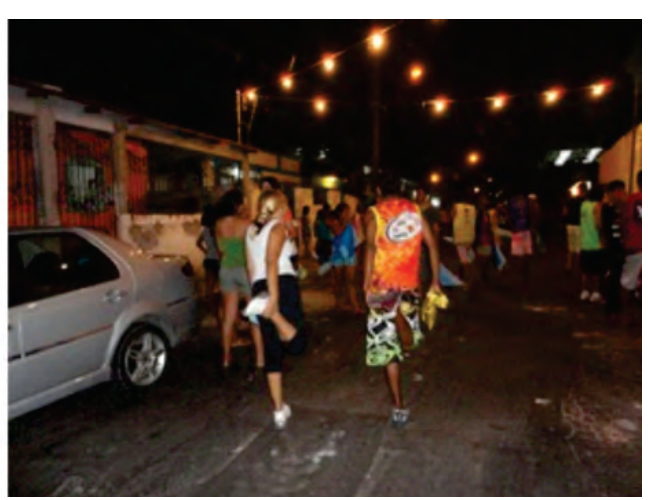

Figura 3. Ensaio da quadrilha. Fonte: Acervo da autora, 2011.

Antes do ensaio, o coordenador reúne os brincantes para prestar alguns informes, importantes, por exemplo, alinhamento na hora da dança, mudança

54 Somanlu, ano 11, n. 1, jan./jun. 2011 
na coreografia conforme a música etc. Os jovens dançam com o lenço nas duas mãos e realizam a coreografia da dança com muita animação, os passos sincronizados são uma das características do trabalho em equipe (Figuras 4 e 5).

Durante o ensaio, os moradores ficam observando os brincantes, na maioria são os próprios familiares que se envolvem (incentivando-os, oferecendo água, guardando os aparelhos celulares etc.) para que os quadrilheiros possam representar da melhor forma sua comunidade, torna-se, portanto, uma festa que marca o trabalho coletivo. A senhora Alda Gonçalves Barros, dona da casa onde ocorre a concentração participa dos ensaios e participa das apresentações nos festivais, acompanhando assim, os brincantes.

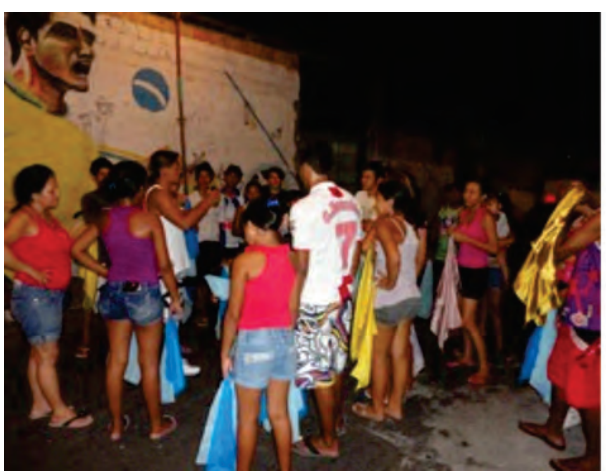

Figura 4. Reunião antes do ensaio. Fonte: Acervo da autora, 2011.

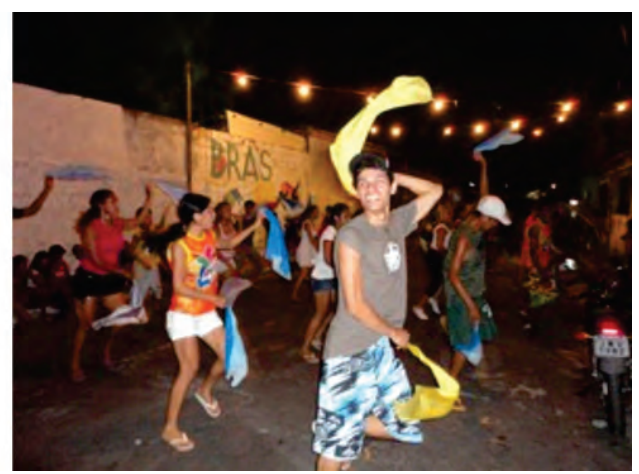

Figura 5. Ensaio da quadrilha. Fonte: Acervo da autora, 2011.

O tema da apresentação do Grupo Folclórico Quadrilha de Duelo em 2011 chamou-se "O Retorno de um justiceiro, a morte está em suas mãos". Trata-se da história de duas gangs rivais que aterrorizam uma pequena cidade sem lei. Uma é liderada pelos justiceiros e outra pelos mexicanos. A encenação é realizada pelos "duelistas", formada pelo dono do bar, capanga, pistoleiro, mexicano etc. (Figura 6).

As indumentárias dos personagens apresentam-se com cores variadas, como ponche vermelha com fitas gregas, brilhantes, franjas com cores variadas, copão e chapéus, botas, cada um desses personagens trazem consigo indumentárias diferentes cada uma com suas cores. As roupas das mulheres

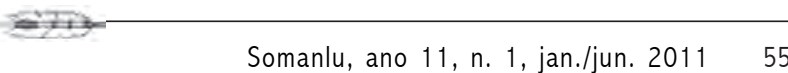


são bem coloridas, cheias de lantejoulas, perolas, pedras d'águas, colares, lenços etc. Os homens usam sapato social e lenços nas mãos (Figura 7).

Os personagens da quadrilha de duelo "Anjos do Faroeste" são formados da seguinte forma: duelistas; destaques (seis casais): rei e a rainha, príncipe e a princesa, viúvos, anjos do faroeste, mocinho e mocinha; e brincantes comuns. Eles trazem cores variadas de acordo com o tema.

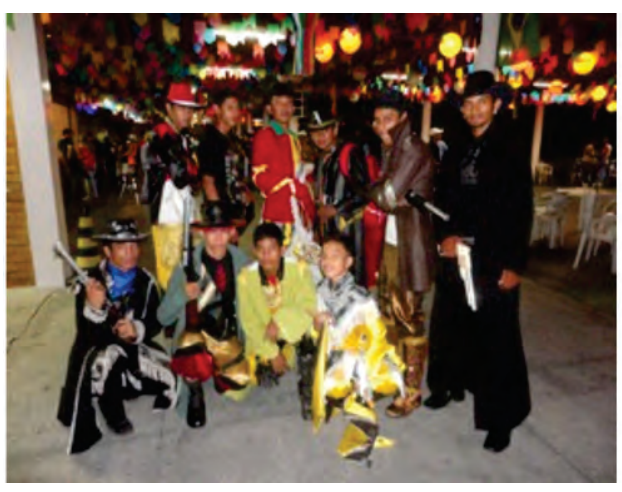

Figura 6. Os duelistas.

Fonte: Acervo da autora, 2011.

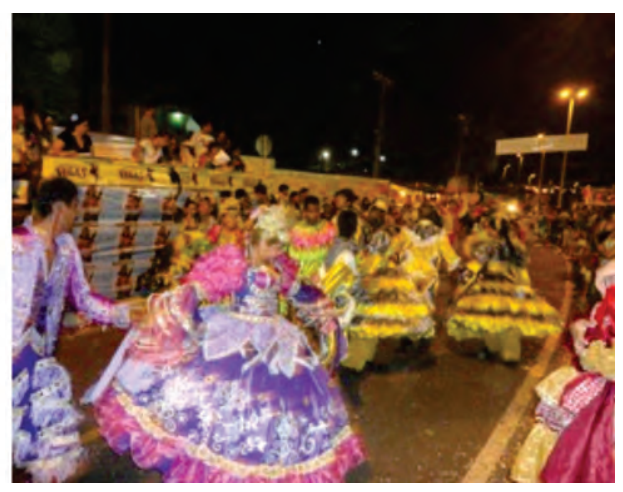

Figura 7. Apresentação da quadrilha. Fonte: Acervo da autora, 2011.

Já o musical da quadrilha são formados por seis músicas, com a participação das bandas Trio Virgulino e Mastruz com leite, enfatizando que, a cada passagem de músicas tem uma vinheta da quadrilha.

O coreógrafo da quadrilha é o próprio criador e coordenador do grupo folclórico, o senhor Rosinaldo Lopes, responsável pelos ensaios do grupo folclórico de duelo "Anjos do Faroeste". Observei que a maioria da coreografia apresentada é de quadrilha tradicional, exemplo: cumprimento ao público, a formação da grande roda, túnel de quatro filas, trancilim entre homens e mulheres, formação de duas filas retas, jogada de lenço entre homens e mulheres e batida de pés etc.

Os adereços que compõe a peça teatral são mesas, cadeiras, um bar, revolver de madeira e dublagem; da quadrilha são compostos por 12 leques pequenos, que é usado na hora da dança dos quadrilheiros. 
Para a realização do Circuito de Festivais Folclóricos, a Prefeitura libera uma verba para os bairros participantes, que ficam encarregados oferecer a estrutura física, o contrato de bandas, os transportes aos grupos folclóricos, organizar as apresentações etc.

Durante o trabalho de campo, no qual ocorreu durante o período de 4 de junho à 4 de julho de 2011, acompanhei a trajetória da quadrilha de duelo "Anjos do faroeste" nas apresentações. Ônibus especial fornecido por cada festival transportava os brincantes e sua coordenação ao local de apresentação. A saída e chegada do transporte era sempre na concentração do grupo, localizada na Rua Ermano Estradelli, Bairro São Jorge.

O grupo folclórico quadrilha de duelo "Anjos do Faroeste" realizou apresentações em vários eventos promovidos pela Prefeitura Municipal de Manaus, ou seja, no Circuito de Festivais Folclóricos que acontecem em diferentes bairros (Parque 10 de Novembro, Nova Esperança etc.) e em locais particulares (Fabrica do Polo Industrial Yamaha), quanto em festivais de bairros promovidos pela comunidade (Festival da Graúna) (Quadro 1). Os locais de apresentações do Grupo Folclórico Quadrilha de Duelo Anjos do Faroeste estão especificadas no quadro abaixo (Quadro 1).

A quadrilha possui um blog que foi criado pela pesquisadora e que está sendo atualizado pela quadrilheira Gleiciane da Silva Pereira e facebook. Neles são publicados imagens e mensagens sobre a quadrilha. O blog e o facebook, por ser um espaço interativo disponível na Internet utilizado como ferramenta pedagógica de apoio ao processo educativo, atrai muitos jovens, assim, com a sua divulgação, a sociedade em geral pode acompanhar o trabalho que é realizado com o Grupo Folclórico Quadrilha de Duelo Anjos do Faroeste que pertence a comunidade do Bairro São Jorge (ALBUQUERQUE; MATTER, 2010).

Como podemos observar este grupo folclórico gradativamente vai oferecendo a sociedade amazonense o fruto de um trabalho coletivo que expressa a vontade de populares para oferecer diversão e propagar eventos culturais. 


\begin{tabular}{|c|c|c|c|c|}
\hline $\mathbf{N}^{\circ}$ & Data & Bairro & Zona & Observação \\
\hline 1. & $17 / 06 / 2011$ & $\begin{array}{l}\text { Distrito } \\
\text { Industrial I }\end{array}$ & Sul & $\begin{array}{l}\text { A Fabrica do Polo Industrial } \\
\text { Yamaha, ofereceu uma festa de } \\
\text { confraternização aos funcionários } \\
\text { e familiares, como apresentação } \\
\text { principal a apresentação da quadri- } \\
\text { lha de duelo "Anjos do Faroeste". }\end{array}$ \\
\hline 2. & $17 / 06 / 2011$ & $\begin{array}{l}\text { Praça } 14 \text { de } \\
\text { Janeiro }\end{array}$ & Sul & $\begin{array}{l}\text { O grupo se apresentou no Festi- } \\
\text { val do Graúna, na Rua Afonso } \\
\text { Pena, próxima a Av. Nhamundá. } \\
\text { A rua fica interditada na sexta feira } \\
\text { e nos finais de semana a noite. } \\
\text { Além da quadrilha de duelo, há } \\
\text { apresentação de outros grupos fol- } \\
\text { clóricos: quadrilhas tradicionais e } \\
\text { cômicas, cirandas, danças interna- } \\
\text { cionais etc. }\end{array}$ \\
\hline 3. & $18 / 06 / 2011$ & $\begin{array}{l}\text { Santo } \\
\text { Agostinho }\end{array}$ & Oeste & $\begin{array}{l}\text { O grupo de apresentou no tabla- } \\
\text { do que fica numa área aberta no } \\
\text { bairro (campinho de futebol). A } \\
\text { festa foi organizada por morado- } \\
\text { res da região. }\end{array}$ \\
\hline 4. & $18 / 06 / 2011$ & Compensa II & Oeste & $\begin{array}{l}\text { Apresentação especial no Circuito } \\
\text { de Festivais Folclóricos. }\end{array}$ \\
\hline 5. & $19 / 06 / 2011$ & Nova Esperança & Oeste & $\begin{array}{l}\text { Apresentação no Circuito de Fes- } \\
\text { tivais Folclóricos, o grupo compe- } \\
\text { tiu com os demais grupos de sua } \\
\text { categoria (quadrilha de duelo). }\end{array}$ \\
\hline 6. & $23 / 06 / 2011$ & $\begin{array}{l}\text { Parque } 10 \text { de } \\
\text { Novembro }\end{array}$ & Centro-Sul & $\begin{array}{l}\text { Apresentação no Circuito de Fes- } \\
\text { tivais Folclóricos, o grupo compe- } \\
\text { tiu com os demais grupos de sua } \\
\text { categoria (quadrilha de duelo). }\end{array}$ \\
\hline 7. & $25 / 06 / 2011$ & Japiim & Sul & $\begin{array}{l}\text { Circuito de Festivais Folclóricos- } \\
\text { o grupo esteve presente no even- } \\
\text { to, mas não se apresentaram. }\end{array}$ \\
\hline 8. & $26 / 06 / 2011$ & Alvorada II & Centro-Oeste & $\begin{array}{l}\text { A festa foi organizada por mora- } \\
\text { dores da região. O grupo compe- } \\
\text { tiu com os demais grupos de sua } \\
\text { categoria (quadrilha de duelo). }\end{array}$ \\
\hline
\end{tabular}




\begin{tabular}{|l|c|l|l|l|}
\hline N. & Data & \multicolumn{1}{|c|}{ Bairro } & Zona & \multicolumn{1}{c|}{ Observação } \\
\hline 9. & $01 / 07 / 2011$ & $\begin{array}{l}\text { Parque 10 de } \\
\text { Novembro }\end{array}$ & Centro-Sul & $\begin{array}{l}\text { Apresentação especial no Circuito } \\
\text { de Festivais Folclóricos, não hou- } \\
\text { ve disputa. }\end{array}$ \\
\hline 10. & $01 / 07 / 2011$ & Vila da Prata & Oeste & $\begin{array}{l}\text { Apresentação no Circuito de Festi- } \\
\text { vais Folclóricos, o grupo compe- } \\
\text { tiu com os demais grupos de sua } \\
\text { categoria (quadrilha de duelo). }\end{array}$ \\
\hline 11. & $02 / 07 / 2011$ & São Jorge & Oeste & $\begin{array}{l}\text { A festa foi organizada por mora- } \\
\text { dores da região. }\end{array}$ \\
\hline 12. & $02 / 07 / 2011$ & São Jorge & Oeste & $\begin{array}{l}\text { A festa foi organizada pelo Circu- } \\
\text { lo Militar de Manaus - Cirmman, } \\
\text { com a finalidade de realizar uma } \\
\text { confraternização entre militares, } \\
\text { familiares e comunidade. }\end{array}$ \\
\hline 13. & $02 / 07 / 2011$ & São Francisco & Sul & $\begin{array}{l}\text { Apresentação especial no Circuito } \\
\text { de Festivais Folclóricos, não hou- } \\
\text { ve disputa. }\end{array}$ \\
\hline
\end{tabular}

Quadro 1. Locais de apresentações da quadrilha de duelo "Anjos do Faroeste".

Fonte: Quadro elaborado pela autora, estudo in loco, 2011.

O grupo de quadrilha de Duelo Anjos do Faroeste competia com outros grupos da mesma categoria nos festivais folclóricos. Em alguns locais, apenas apresentavam juntamente com vários grupos folclóricos. Geralmente, os coordenadores do evento ofereciam, após a apresentação, água para os brincantes. Em alguns casos, foi oferecido lanches.

Pode-se considerar que o trabalho realizado segue os fundamentos da interpretação antropologia que leva a uma leitura do que acontece: um poema, uma pessoa, uma historia, um ritual, uma instituição, podendo se estender a um descrição de um grupo folclórico, ou seja, a interpretação ocorre em todos os momentos do estudo, da leitura do "texto", pleno de significado, que é a sociedade na escrita do texto/ensaio do antropólogo, por sua vez interpretado por aqueles que não passaram pelas experiências do autor do texto escrito (GEERTZ, 2011). 


\section{Notas}

${ }^{1}$ Segundo Apolo11: “O solstício também é marcado por ser o dia mais longo do ano [...]. Durante o Solstício de Verão, a inclinação do eixo no hemisfério Sul, faz com que as regiões abaixo da linha do Equador sejam mais atingidas pelos raios do Sol. Por outro lado, o hemisfério Norte do planeta estará sendo menos favorecido, com menor incidência solar. Ou seja, enquanto nós comemoramos a chegada do verão, os habitantes do hemisfério norte comemoram o início do inverno)". Disponível em: http://www.apolo11.com. Acesso em: 5/5/2011.

${ }^{2}$ A Superintendência da Zona Franca de Manaus (Suframa) é uma Autarquia vinculada ao Ministério do Desenvolvimento, Indústria e Comércio Exterior que administra a Zona Franca de Manaus - ZFM, com a responsabilidade de construir um modelo de desenvolvimento regional que utilize de forma sustentável os recursos naturais, assegurando viabilidade econômica e melhoria da qualidade de vida das populações locais. Fonte: http://www.suframa.gov.br/ suframa_o_que_e_suframa.cfm. Acesso em: 9 jul. 2011.

${ }^{3}$ Patrimônio Cultural Imaterial são as práticas, representações, expressões, conhecimentos e técnicas que as comunidades, os grupos e, em alguns casos, os indivíduos reconhecem como parte integrante de seu patrimônio cultural.

${ }^{4}$ O Centro de Convenções é administrado pela Secretaria de Estado de Cultura do Amazonas. Popularmente conhecido como Sambódromo, por sediar os Desfiles das Escolas de Samba de Manaus.

${ }^{5} \mathrm{O}$ faroeste é um gênero cinematográfico que sempre primou por dualidades bem claras, procurando distinguir a civilização norte-americana.

${ }^{6} \mathrm{O}$ duelo é uma disputa em combate de confronto entre duas pessoas, motivadas, em geral, por desagravo à honra, desavenças individuais, familiares, em facções ou grupais, e outros tipos de confronto de cunho fortemente emocional, tais práticas são de e em geral, somente de cunho fortemente emocional. Várias são as formas do duelo, inclusive sem a utilização de armas brancas ou de fogo; na forma de luta livre, ou também chamada "Apache", dentro de um círculo (às vezes de fogo, as noturnas).

${ }^{7} \mathrm{O}$ histórico a que nos referimos é parte de acervo documental do grupo folclórico.

${ }^{8}$ Rosinaldo Lopes é o criador e coordenador do Grupo Folclórico Quadrilha de Duelo “Anjos do Faroeste".

${ }^{9}$ Coordenador e brincante da Quadrilha de Duelo "Anjos do Faroeste".

${ }^{10}$ Relativo ao vestuário dos quadrilheiros.

${ }^{11}$ Ermano Stradelli nasceu em Borgotaro (Itália), em 1852, e morreu em Manaus no ano de 1926. Além de registros escritos, deixou também muitas fotografías dos lugares pelos quais passou no Brasil durante suas explorações. O primeiro registro de Stradelli iniciou-se a partir de sua saída de Manaus, no dia primeiro de janeiro de 1888. Contudo, para os propósitos deste estudo, nos deteremos em sua viagem de 1889, quando o naturalista parte de Manaus, através de matas e

60 Somanlu, ano 11, n. 1, jan./jun. 2011 
florestas do Rio Branco. Site: http://www.triplov.com/novaserie.revista/ana_luisa_janeira/ haddad_e_fusaro/index.html. Acesso em: 23/6/2011.

${ }^{12}$ Endereço de acesso do blog: http://osanjosdofaroeste.blogspot.com/; Endereço do facfebook: http://www.facebook.com/quadrilha.osanjosdofaroeste.

${ }^{13}$ Clifford Geertz é considerado o fundador de uma das vertentes da antropologia contemporânea - a chamada Antropologia Hermenêutica ou Interpretativa.

\section{Referências}

ALBUQUERQUE, Teresa Kátia; MATTER, Nely. Mídia: recursos didáticos. In: Licenciatura em Artes Visuais: tecnologias contemporâneas na escola 2. Módulo 2. Brasília, 2010. Séries GTArtes.

AMARAL, Rita. Festa à Brasileira: sentidos do festejar no país que "não é sério", 1998. Disponível em: <http://www.aguaforte.com/antropologia/ festaabrasileira/festa.html. Acesso em: 21 jun. 2011.

CASCUDO, Luis da Câmara. Dicionário do folclore brasileiro. 10. ed. São Paulo: Global, 2001.

CHIANCA, Luciana. Quadrilhas juninas: A aventura de uma dança palaciana no Brasil. 2010. p. 10. Disponível em: <http:// www.univesp.ensinosuperior.sp.gov.br/preunivesp /186/quadrilhasjuninas.html>. Acesso em: 17 maio 2011.

Quando o campo está na cidade: migração, identidade e festa. Sociedade e cultura, janeiro-junho, ano/vol. 10, número 001. Universidade Federal de Goiás: Gioania-Brasil, 2007. Disponível em: < http://redalyc.uaemex.mx/ pdf/703/70310106.pdf>. Acesso em: 5 nov. 2010.

FETEC - Fundação de Educação, Turismo, Esporte e Cultura de Boa Vista. Inventário do Patrimônio Cultural de Boa Vista. Boa Vista: Ióris, 2011.

GEERTZ, Clifford. A interpretação das culturas. Rio de Janeiro: LTC, 2011.

GOVERNO DO ESTADO DO AMAZONAS, 2005. Patrimônio Cultural:

Patrimônio Cultural Imaterial. Disponível em: <http:// 
www.culturamazonas.am.gov.br/programas_02.php?cod=0862>. Acesso em: 1 jun. 2011.

HISTÓRICO. Quadrilha os Anjos do Faroeste. Manaus-AM, 2011. Mimeo.

IPHAN - Instituto do Patrimônio Histórico e Artístico Nacional. Registro de bens culturais de natureza imaterial. Disponível em: < http:// portal.iphan.gov.br>. Acesso em: 1 jun. 2011.

MALINOWSKI, Bronislaw. Argonautas do Pacífico Ocidental. São Paulo: Abril S.A. Cultural e Industrial, 1976.

RIO, João do. A alma encantadora das ruas: crônicas. São Paulo: Editora Martin Claret Ltda., 2007.

SEMCOM. Secretaria Municipal de Comunciação. $2^{\circ}$. Circuito de festivais folclóricos já agira a cidade. Disponível em: http://www.manaus.am.gov.br. Acesso em: 3 Jul. 2011.

SILVA, Alvatir Carolino da. Festa dá trabalho!: As múltiplas dimensões do trabalho na organização e produção de grupos folclóricos da cidade de Manaus. Dissertação (Mestrado em Sociedade e Cultura na Amazônia) - Instituto de Ciências Humanas e Letras, Universidade Federal do Amazonas, Manaus, 2009. VADE MECUM (Org. Anne Joyce Angher). Vade Mecum acadêmico de direito Rideel. 11. ed. São Paulo: Rideel, 2010. 